\title{
Isolated Bacteria from Hemodialysis Water Distribution Systems in Hemodialysis Centers in Bandung
}

\author{
Mohd Hafeez bin Mohd Rafee, ${ }^{1}$ Sunarjati Sudigdoadi, ${ }^{2}$ Julius B. Dewanto ${ }^{3}$ \\ ${ }^{1}$ Faculty of Medicine, Universitas Padjadjaran, ${ }^{2}$ Departmen of Microbiology \& Parasitology \\ Faculty of Medicine Universitas Padjadjaran, ${ }^{3}$ Department of Biochemistry \& Molecular Biology \\ Faculty of Medicine, Universitas Padjadjaran
}

\begin{abstract}
Background: Despite the advent of water treatment technology for the past few decades, bacterial contamination is still an everlasting issue that requires solid intervention. Many studies across the world have identified myriad of bacteria that colonized the hemodialysis water distribution system. This study was conducted to identify common bacteria that colonized the hemodialysis water distribution systems in Bandung.

Methods: This was a descriptive laboratory study conducted at the Department of Microbiology Faculty of Medicine Universitas Padjadjaran in 2014. Sterile bottles were used to collect 16 samples of reverse osmosis water from 2 hemodialysis centers in Bandung. Approximately $15 \mathrm{ml}$ of water volume was collected in each bottle from 7 standard points for water sampling in hemodialysis system. The samples were first inoculated into R2A agar by pour-plate method and colonies grew were sub-cultured onto MacConkey and blood agar and the identification was based on Gram stain morphology, colony characteristics, and biochemical tests. Results: Micrococcus luteus and Pseudomonas sp. were the two predominant organisms which colonized the hemodialysis water distribution system. In addition, some genus of the Enterobacteriaceae such as Enterobacter aerogenes, Klebsiella pneumoniae, and Yersinia pseudotuberculosis were also isolated from the entire system based on the standard points of sampling.

Conclusions: Bacterial contamination in the hemodialysis water distribution system in Bandung is still a major problem regardless of the efforts utilized to minimize it. [AMJ.2016;3(2):259-64]
\end{abstract}

Keywords: Bacteria, hemodialysis, reverse osmosis, water

\section{Introduction}

It is widely acknowledged that one of the biggest challenges in hemodialysis is sustaining optimal sterility of the prepared water. In the era before the birth of reverse osmosis system, tap water was used for dialysis fluid to mainly treat acute cases. ${ }^{1}$ Hemodialysis is an extra-corporeal therapy that is prescribed to reduce the signs and symptoms of uremia and to replace partially a number of the key functions of the kidneys when they are no longer sufficient to maintain patient's wellbeing or life. ${ }^{2}$ It is estimated that patients of hemodialysis are generally exposed to 400 liters of water which is utilized for dialysis fluid weekly. ${ }^{3}$ This colossal exposure places the patients at risk of infection by a plethora of pathogenic and opportunistic bacteria.
Theoretically, reverse osmosis water used in hemodialysis should be free of microorganisms. Unfortunately, even with the minute pore-sized filtration membranes, bacterial contamination is still an everlasting issue in the field of hemodialysis. Many studies across the globe have isolated many bacteria from reverse osmosis water distribution systems and most of them were opportunistic bacteria that might cause in hemodialysisrelated infections. ${ }^{4}$ The most predominant isolated bacteria were Pseudomonas aeruginosa and Acinetobacter species. ${ }^{5}$ There is no data found exist, however, regarding bacterial contamination in hemodialysis water distribution systems in Indonesia. Thus, it is important to explore the possibility of contamination of the hemodialysis water distribution systems in hemodialysis centers located in Bandung. In addition to that, this

Correspondence: Mohd Hafeez bin Mohd Rafee, Faculty of Medicine, Universitas Padjadjaran, Jalan Raya BandungSumedang Km.21, Jatinangor, Sumedang, Indonesia, Phone: +6287827958720 Email: hafeezrafee@gmail.com 
study was specifically carried out to determine the species of bacteria that colonize the hemodialysis water distribution systems in Bandung.

\section{Methods}

This was a descriptive laboratory study conducted in 2014. The samples were collected from the hemodialysis water distribution systems in 2 separate hemodialysis centers in Bandung. This study had been approved by the Health Research Ethics Committee Faculty of Medicine, Universitas Padjadjaran Bandung. First of all, 11 samples of water were collected from center $A$ and 5 samples were collected from center B using sterile bottles at the beginning of a dialysis treatment. Each sample was collected at approximately $15 \mathrm{ml}$ and was taken using clean-catch method.

The samples consist of a series of sampling in each of the 7 points in the water system: (I) point where water leaves the reverse osmosis machine, (II) point where water leaves the reverse osmosis tank, (III) return line of reverse osmosis loop, (IV) point where water enters the dialyzer, (V) point where water enters equipment used to prepare bicarbonate and acid concentrate, (VI) point where dialysis machine is hooked up to the product water loop, and (VII) point where municipal water supply enters the hemodialysis water system. ${ }^{6}$ In center $A$, one sample was collected from point $1,2,3,5$, and 7 , two samples were collected from point 4 , and four samples were collected from point 6 as there were several circuits of dialysis machines. On the other hand, in center $B$, a sample was collected from point 1, 3, 4, 6, and 7. Each sample was collected after 3-5 minutes of free flow in high flow rate. ${ }^{7}$ Samples were then processed at the Department of Microbiology, Faculty of Medicine, Universitas Padjadjaran within 2 hours.

The samples were inoculated into R2A agar using pour-plate method while the agar was still in liquid form at approximately $40^{\circ} \mathrm{C}$ and were incubated for 24 hours at $37^{\circ} \mathrm{C}$. Colonies were then sub-cultured onto MacConkey agar (MAC) and blood agar (BAP) for 24 hours at $37^{\circ} \mathrm{C}$ and colony characteristics were distinguised. Gram staining was conducted for all grown colonies on MAC and BAP. After that, colonies that grew on MAC were cultured into citrate agar, motility-indole-urease agar, and Klieger iron agar for biochemical tests to determine genus and species based on the growth characteristics. On a separate matter, colonies grew on BAP were tested for catalase and then tested for novobiocin susceptibility

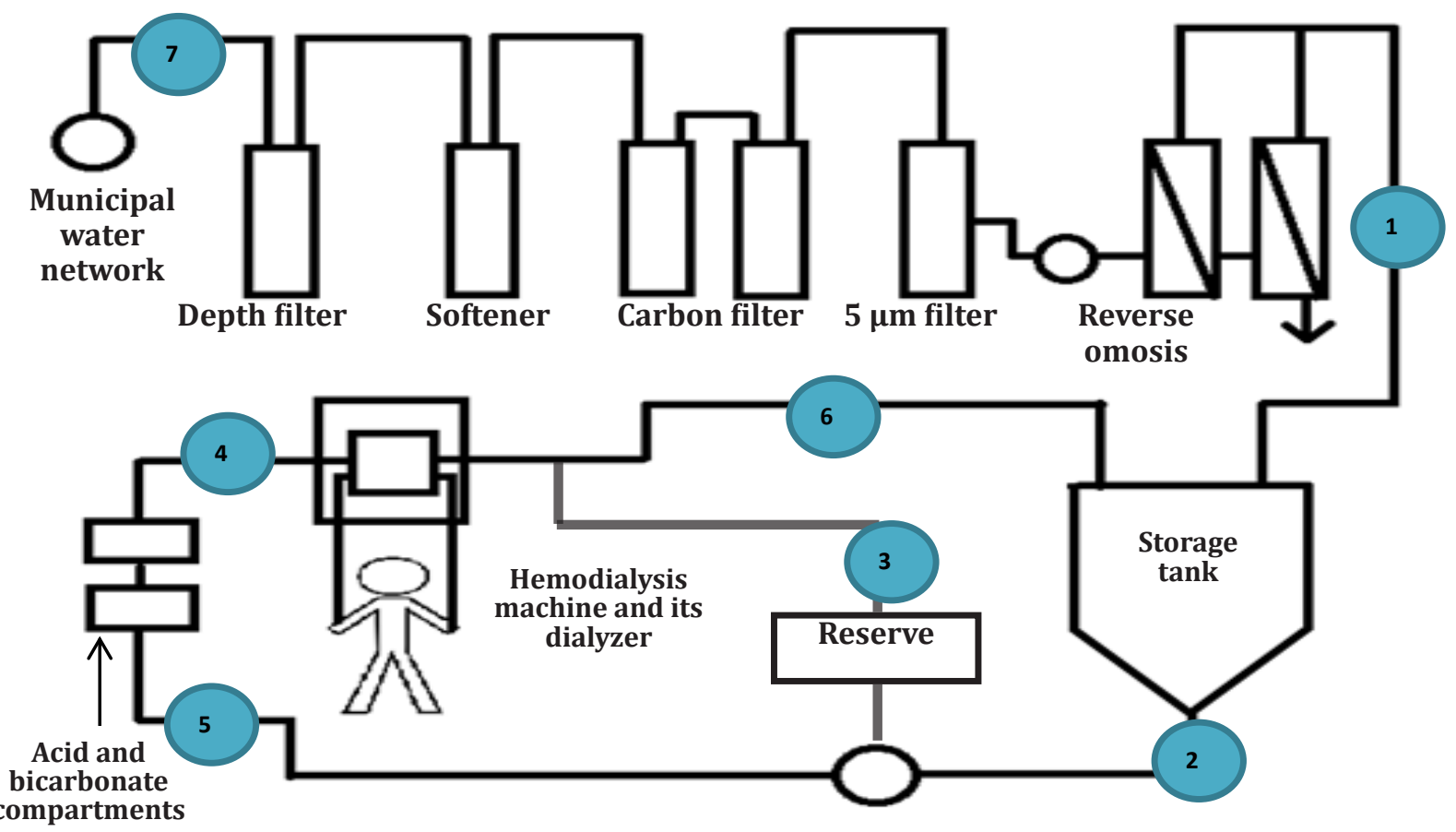

Figure 1 Schematic Diagram of The Sampling Points From The Hemodialysis Circuits in The Centers Studied 
Table 1 Identified Bacteria Genus/Species and Their Corresponding Isolates

\begin{tabular}{lc}
\hline \multicolumn{1}{c}{ Bacteria Genus/Species } & Number of Isolates \\
\hline Micrococcus luteus & 10 \\
Pseudomonas sp. & 6 \\
Acinetobacter sp. & 5 \\
Bacillus sp. & 5 \\
Serratia sp. & 3 \\
Yersinia pseudotuberculosis & 3 \\
Enterobacter aerogenes & 2 \\
Citrobacter diversus & 2 \\
Klebsiella pneumoniae & 2 \\
Moraxella sp. & 1 \\
Staphylococcus epidermidis & 1 \\
Staphylococcus saphrophyticus & 1 \\
Total & 41 \\
\hline Note: Sp.: species &
\end{tabular}

on Mueller-Hinton agar and incubated for 24 hours at $37^{\circ} \mathrm{C}$.

\section{Results}

From the 16 collected water samples, it was found out that there were 41 isolates of bacteria with 10 isolates identified as Micrococcus luteus and 6 isolates identified as Pseudomonas species.

Three Gram of positive bacteria was identified; Micrococcus luteus, Bacillus sp., $S$. epidermidis, and S. saphrophyticus. Eight Gram of negative bacteria were identified as; (a) Non-enterobacteriaceae; Pseudomonas sp., Moraxella sp., and Acinetobacter sp.; and (b) Enterobacteriaceae; Serratia sp., Yersinia pseudotuberculosis, Enterobacter aerogenes, Citrobacter diversus, and Klebsiella pneumoniae.

\section{Discussion}

Hemodialysis is a promising therapy in ensuring the continuing health of endstage renal disease (ESRD) patients. It was designed to improve patient's quality of life yet economically attenuated the cost for endstage renal disease treatment expenditure. Subsequently, the enhancement of patient safety with more than one dialysis session per week led to the adoption of the current standard of the thrice-weekly dialysis regimen. ${ }^{8}$ The water which is supposed to be ultrapure and contains less than $100 \mathrm{CFU} /$ $\mathrm{ml}$ bacteria has somewhat been proven quite the opposite. ${ }^{4,9}$ In this study, myriad of bacteria has been found to contaminate the hemodialysis water distribution systems in hemodialysis units at Bandung. These bacteria were abundantly found in the municipal water networks in hospitals or distribution pipes which they usually colonized and formed biofilms as shown by previous studies. ${ }^{4,10}$ All of the seven points of standard sampling points used in this study were contaminated and dreadfully up to the point where the municipal water supply enters the hemodialysis system

In hemodialysis, the source of water used to make up the dialysate is basically drinking water which is first purified by various methods; the composition and quality of this water depends on its origin. ${ }^{3}$ Over the last two decades, there has been considerable progress in our understanding of microbial pathogenesis related to hemodialysis in which the current emphasis is on patient immunity, bacterial virulence, and the dialysis process itself. This study prognosticates the upcoming problems to the patients as they concurrently suffer from weakened immune system primarily from the firsthand effects of uremia making them prone to infections. ${ }^{4}$ In addition to direct tissue damage by infection, a number of bacterial products such as lipopolysaccharides (LPS), exotoxins, and peptidoglycans share the ability to induce cytokines release and are 
known activators of immune functions. ${ }^{11}$

In the beginning of water treatment, municipal water supply will be distributed through mechanical filters, water softener, carbon filters, deionizers, reverse osmosis modules, and finally to the storage tanks that is ready to be distributed to the whole system using polyvinyl chloride (PVC) tubing., ${ }^{2,4}$ Reverse osmosis module itself is a ground breaking membrane-based technology to purify water by separating the dissolved solids from the feed stream resulting in permeate and reject stream, where water permeates the minute pores of the membranes and is delivered as purified water called permeate water. $^{12,13}$

Despite their capacity to even filter bacteria and their products, contamination is not impossible to remain as a major stirring issue in hemodialysis water treatment system. ${ }^{1}$ Astonishngly, it has been shown by Goosen et al. ${ }^{14}$ in their study that bacteria are able to pass through the microfiltration membranes in waste water applications. In addition, membranes with pore sizes smaller than 0.2 $\mu \mathrm{m}$ are still capable of transmitting secondary effluent cells. It is significant to point out that the study showed up to $1 \%$ of the bacteria in the feed which can pass to the permeate side. Nonetheless, while a significant portion of the cells in the permeate side showed biological activity, none of the cells were able to reproduce.

Besides that, it has been speculated that certain naturally occurring Gram-negative bacteria are able to multiply in relatively pure reverse osmosis water and stagnant water in the distribution pipes downstream which can be a major source of bacterial contamination and endotoxin products. ${ }^{4,5,15}$ In addition to that, stagnant water provides felicitous niche for the bacteria to form biofilms on the membrane and further lead to the fouling of the reverse osmosis system. ${ }^{5}$

Conventional spiral wound modules in most reverse osmosis system use brine seals to separate the feed and side-product of the membrane in the pressure vessel. Consequently, the use of these materials creates stagnant areas surrounding the membrane which are difficult to be disinfected adequately. As a result, contamination of this area often leads to bypass of bacteria through the brine seals causing contamination to occur in the entire system. It has been proposed that the use of membrane module designs that eliminate brine seals is more effective in cleaning and sanitizing which eventually reduces the possibility of bacteria bypassing the membrane. ${ }^{16}$

Based on the Association for the Advancement of Medical Instrumentation (AAMI) and Japanese Society for Dialysis Therapy, the high viable counts $(>100 \mathrm{CFU} /$ $\mathrm{ml}$ ) detected in this study indicate that the microbiological quality of the water analyzed was well beyond the limit. 4,17 The water was contaminated by both Gram positive bacteria and Gram negative bacteria. The most predominant bacteria was Micrococcus luteus. Besides that, the water in hemodialysis distribution systems was also abundant with Enterobacteriaceae and other Gram negative bacteria such as Pseudomonas species and Acinetobacter species. Most of these bacteria are environmental bacteria and abundantly found in soil, water, skin, and medical equipment where they tend to colonize. Montanari et al. ${ }^{4}$ discovered similar bacteria found in hemodialysis water distribution system in São Paolo. Furthermore, various studies across the globe showed that the most predominant bacteria in hemodialysis water were Acinetobacter sp. and Pseudomonas aeruginosa. It is important to note that these bacteria often form biofilms and exhibit remarkable resistance to common disinfectants used at most hemodialysis centers. ${ }^{5}$

As previously stated, bacteria and their products are known to be the activator of immune system. Furthermore, many of these products have been shown to bypass high-flux membranes and could be transferred by backdiffusion from the dialysis fluid to the blood compartment in the hemodialysis machine. ${ }^{18}$ This direct contamination of dialysate and the subsequent shift of bacterial products to the blood site is an important cause for microinflammation in hemodialysis patients. ${ }^{19}$ This is an alarming issue as hemodialysis patients are exposed to huge amount of water each week which directly makes contact with the circulatory system.

Moreover, bacterial contact and their products have significant impact to patients in both short and long term. As such, patients with end-stage renal disease have weak immune system and infection caused by these bacteria is unavoidable. This will result in prolonged hospitalization and ultimately increases the cost of treatment. Health care providers need to allocate more resources on this matter and will disrupt the balance of service provided. In addition, inappropriate patient's management, such as antibiotics and ineffective disinfectant used to clean the 
system, will further deteriorate the condition of the patients and ultimately lead to increase in bacterial resistance to both antibiotics and disinfectant.

Unfortunately, there were several limitations for this study. Firstly, this study received limited research fund causing identification of most species of bacteria difficult to be carried out. Secondly, one of the hemodialysis centers studied lack several standard points for water sampling common in hemodialysis. Therefore, adequate sampling for the study of the hemodialysis water distribution systems was not possible and samples were only taken from points that were available during sampling.

This study hopefully will unearth the problems in hemodialysis and in the long run, reduce hemodialysis-related infections and systemic inflammatory response syndrome (SIRS) observed in patients on dialysis treatment. It is widely accepted that the dialysis fluid quality depends on a complex chain of devices, procedures and the quality control implemented. ${ }^{4}$ In most official recommendations, no claims for disinfection are highlighted, but the major focus is on microbiological analysis. It is indeed a step backward since recommendations for disinfection are more important since quality comes from action not verification..$^{20}$

This study showed that the hemodialysis centers have yet to achieve the microbiological standard in hemodialysis. Periodic monitoring of the systems should be carried out to maintain the optimal sterility of the water. Thus, it is crucial to determine the appropriate disinfectant to be used in cleaning the distribution systems and regular maintenance of the system should be carried out.

In conclusion, hemodialysis water distribution systems in Bandung are colonized with myriad of bacteria consisting both Gram negative and Gram positive bacteria. As this is the first official study conducted in Bandung, this elucidates that the standard of water used in the hemodialysis centers do not reach the benchmark provided by AAMI and Japanese Society of Dialysis Therapy.,17 This will result in many unwanted complications as hemodialysis patients are categorized as immunocompromised. ${ }^{11}$ Further studies need to be conducted to identify the species of bacteria that colonize hemodialysis water treatment system and therefore deduce the appropriate methods for maintaining optimal condition for water used in hemodialysis.

\section{References}

1. Ledebo I. Purification of dialysis fluid: historical background and perspective. Blood Purif. 2009;27(Suppl1):17-9.

2. Hakim RM. Hemodialysis. In: Gilbert SJ, Weiner DE, Gipson DS, Perazella MA, Tonelli M, editors. National Kidney Foundations's primer on kidney diseases. 6th ed. Philadelphia: Elsevier; 2014. p. 508-19.

3. Sartori FG, Leandro LF, Montanari LB, de Souza MG, Pires RH, Sato DN, et al. Isolation and identification of environmental mycobacteria in the waters of a hemodialysis center. Curr Microbiol. 2013;67(1):107-11.

4. Montanari LB, Sartori FG, Cardoso MJdO, Varo SD, Pires RH, Leite CQF, et al. Microbiological contamination of a hemodialysis center water distribution system. Rev Inst Med Trop São Paulo. 2009;51(1):37-43.

5. Suman E, Varghese B, Joseph N, Nisha $\mathrm{K}$, Kotian MS. The bacterial biofilms in dialysis water systems and the effect of the sub-inhibitory concentrations of chlorine on them. J Clin Diagn Res. 2013;7(5):84952.

6. Northwest Renal Network. Monitoring your dialysis water treatment system. Seattle, Washington: Northwest Renal Network; 2005.

7. American Public Health Association. In: Eaton $\mathrm{AD}$, Clesceri LS, Greenberg $\mathrm{AE}$, editors. Standard methods for the examination of water and wastewater. 21st ed. Washington: American Public Health Association; 2005.

8. Pierratos A. Long and daily hemodialysis. In: Henrich WL, editor. Principles and practice of dialysis. 4th ed. Philadelphia: Lippincott Williams \& Wilkins; 2009. p. 136-48.

9. Kawanishi H, Masakane I, Tomo T. The new standard of fluids for hemodialysis in Japan. Blood Purif. 2009;27(Suppl1):5-10.

10. Ekrami A, Kayedani A, Jahangir M, Kalantar E, Jalali M. Isolation of common aerobic bacterial pathogens from the environment of seven hospitals, Ahvaz, Iran. Jundishapur J Microbiol. 2011;4(2):75-82.

11. Elkabbaj D, Bahadi A, Cherrah Y, Errasfa M, Eljaoudi R. Impact of improving quality of dialysis fluid on oxidative stress and lipid profile in hemodialysis patients. ISRN Nephrology. 2013;2013:e717849. 
12. Garud R, Kore S, Kore V, Kulkarni G. A Short review on process and applications of reverse osmosis. Univers J Environ Res Technol. 2011;1 (3):233-8.

13. Abid MF, Zablouk MA, Abid-Alameer AM. Experimental study of dye removal from industrial wastewater by membrane technologies of reverse osmosis and nanofiltration. Iranian J Environ Health Sci Eng. 2012;9(1):17.

14. Goosen M, Sablani S, Al-Hinai H, AlObeidani S, Al-Belushi R, Jackson D. Fouling of reverse osmosis and ultrafiltration membranes: a critical review. Separ Sci Technol. 2005;39(10):2261-97.

15. Ward RA. Avoiding toxicity from waterborne contaminants in hemodialysis: new challenges in an era of increased demand for water. Adv Chronic Kidney Dis. 2011;18(3):207-13.
16. Ward RA. Quality management of dialysis fluid for online convective therapies. Contrib Nephrol. 2011;168:78-88.

17. Kawasaki T, Uchino J, Shinoda T, Kawanishi $\mathrm{H}$. Guidance of technical management of dialysis water and dialysis fluid for the Japan Association for Clinical Engineering Technologists. Blood Purif. 2009;27 (Suppl1):41-9.

18. Glorieux G, Neirynck N, Veys N, Vanholder R. Dialysis water and fluid purity: more than endotoxin. Nephrol Dial Transplant. 2012;27(11):4010-21.

19. Schindler R. Clinical effect of purification of dialysis fluids, evidence and experience. Blood Purif. 2009;27(Suppl1):20-2.

20. Nystrand R. Microbiology of water and fluids for hemodialysis. J Chin Med Assoc. 2008;71(5):223-9. 